\title{
C-Reactive Protein Levels Are Elevated in Asthma and Asthma-like Conditions
}

\author{
ANN M. PELLIZZARO, RITA M. HEUERTZ
}

OBJECTIVE: Asthma is a chronic disease involving airway hyperresponsiveness. It was proposed that asthma/chronic shortness of breath elicit chronic systemic inflammation even in the absence of episodic events.

DESIGN: Volunteers completed questionnaires relevant to asthma and/or dyspnea and consented to Creactive protein (CRP) quantitation. Subject groups were: control (no reported dyspnea) and asthma/shortness of breath [dyspnea] group.

SETTING: Studies were performed in the Saint Louis metropolitan area.

PARTICIPANTS: Participants consisted of volunteers aged 18-57. Inclusion criteria were good health, not pregnant, weight $>110$ pounds and absence of antiinflammatory medicine use.

RESULTS: Serum CRP ranged from undetectable to $22,013 \mathrm{ng} / \mathrm{mL}$. Mean results for asthmatic/dyspnea $(\mathrm{n}=22)$ and control $(\mathrm{n}=27)$ groups were 4,203 $\pm 1,323$ $\mathrm{ng} / \mathrm{mL}$ and $1,741 \pm 467 \mathrm{ng} / \mathrm{mL}(\mathrm{p}<0.05)$ respectively.

CONCLUSION: Individuals with asthma/asthma-like symptoms have chronic low levels of systemic inflammation despite the absence of episodic pulmonary events. Understanding chronic systemic inflammation relevant to asthma/asthma-like conditions may lead to design of targeted therapeutics.

ABBREVIATIONS: hsCRP = high sensitivity $\mathrm{C}$ reactive protein

INDEX TERMS: acute phase proteins, airway hyperresponsiveness, inflammation, dyspnea.

Clin Lab Sci 2010;23(4)223
Ann M. Pellizzaro, MT(ASCP), Mayo Clinic, Jacksonville, FL 32224

Rita M. Heuertz, PhD, MT(ASCP), Clinical Laboratory Science Department, Doisy College of Health Sciences, Saint Louis University, St. Louis, MO 63104-1111

Address for correspondence: Rita M. Heuertz, PhD, MT(ASCP), Clinical Laboratory Science Department, Doisy College of Health Sciences, Saint Louis University, 3437 Caroline Street, St. Louis, MO 63104-1111, 314977-8610, FAX: 314-977-8503, heuertzr@slu.edu

\section{INTRODUCTION}

Asthma is a chronic condition affecting individuals in a wide range of ages, races and income levels. This condition currently affects about 300 million people worldwide and that number continues to rise each year. ${ }^{1}$ Characteristic symptoms of the disease include breathlessness, wheezing, coughing and an abnormal breathing pattern. ${ }^{2}$ Once a patient exhibits these characteristic symptoms or even an attack (characterized by tightening of the chest and wheezing), additional testing by a physician is warranted. Asthma is currently diagnosed through a series of tests including lung function assessment, peak flow measurements, chest $\mathrm{x}$ ray and blood tests such as an eosinophil count and arterial blood gas measurement. ${ }^{2}$ Still, this disease often goes undiagnosed and untreated due, in part, to a lack of agreement within the medical community about the mechanism by which asthma occurs.

Research has opened up new possibilities for the causative mechanisms of asthma. Several phenotypic categories for asthmatics have been identified including clinical, trigger and immunopathological. ${ }^{3}$ Clinical phenotypes are those related to the severity and frequency of noticeable symptoms, response to treatment, age of onset and presence of chronic 


\section{RESEARCH AND REPORTS}

restriction. Trigger phenotypes involve the presence of common triggers for asthma symptoms such as aspirin or other anti-inflammatory drugs, environmental or occupational allergens and exercise. Lastly, immunopathological phenotypes are based on the type of inflammatory pattern present, represented by the cell types seen such as polymorphonuclear cells and eosinophils. ${ }^{3}$ Results obtained from the current study are important because they support the hypothesis that systemic inflammation is an important component of asthma/shortness of breath thereby indicating that inflammatory mechanisms are important areas to focus research efforts in the asthma and airway hyperreactivity fields.

Studies have been conducted investigating the role of different inflammatory markers in asthmatics and results support the hypothesis that inflammation is present in this disease. In one study, the acute phase reactant serum amyloid A was found to be significantly elevated in participants with allergic rhinitis and asthma. ${ }^{4}$ This same study also investigated two other inflammatory markers, fibrinogen and C-reactive protein (CRP), that were not found to be significantly different from the control group, though, both groups had elevated levels. Another study by the US National Health and Nutrition Examination Survey (NHANES) specifically evaluated CRP levels in asthmatics and those with asthma symptoms and results indicate that participants who were asthmatic and/or showed symptoms had higher levels of CRP. ${ }^{5}$ Researchers conducting this NHANES study urged that the possibility of using CRP as a marker for judging asthma control and severity should be further explored.

CRP is one of the acute phase reactants whose levels increase in response to inflammation. ${ }^{6}$ At the onset of inflammation, interleukin (IL)- 6 is released into the bloodstream thereby stimulating the production of CRP from hepatocytes. ${ }^{7}$ IL-1 $\beta$ is also released and enhances the effect caused by IL-6, causing a spike in CRP level that can reach as high as 1,000 times the normal value. ${ }^{8}$ Increased CRP levels have been associated with many conditions such as cardiovascular disease, obesity, smoking and diet/nutritional status. ${ }^{9}$ Current thought in asthma research is that, due to the chronic inflammatory component of the condition, CRP levels are also stimulated and remain elevated in these individuals over their lifetime. $^{6}$

In the current study, a link between serum CRP levels and asthma and chronic breathlessness was determined. While it is recognized that various disorders can cause shortness of breath as well as elevated serum CRP values, the task was to ascertain whether a single-point assessment of serum CRP in combination with a selfreport of chronic breathlessness was of clinical value or usefulness. Many physicians are reticent to make a definitive diagnosis of asthma for many reasons; therefore, identification of one group of study participants as diagnosed asthmatics/self-reported chronic shortness of breath and a second group as nonasthmatic/no self-report of breathlessness were categorical distinctions addressing the above-defined task in this population of predominantly 18-22 year olds.

Using a study population located in the Midwest United States, serum CRP levels were determined in two distinct groups, physician-diagnosed asthmatics/ participants reporting frequent shortness of breath and nonasthmatic/shortness of breath participants. The addition of a self-reporting questionnaire assisted in ruling out interfering conditions known to increase CRP levels as well as assisted in gathering helpful participant history. The goal of the current study was to provide clarity to the complex relationship between CRP and asthma and also to potentially introduce a testing route useful for inclusion in the testing regimen for asthma diagnosis.

\section{MATERIALS AND METHODS}

\section{Study Population}

Subjects between the ages of 18 and 80 were recruited from a Midwestern population based in St. Louis, Missouri. Study recruits qualified for inclusion in the Institutional Review Board-approved study if they were not pregnant, weighed greater than 110 pounds, had no fever, were free from the use of anti-inflammatory medications and were generally in good health (defined by self-report). Determination of asthma diagnosis and/ or symptoms was made using a questionnaire that subjects completed upon entry into the study. Responses to questions revealed whether the study 


\section{RESEARCH AND REPORTS}

recruits had a history of asthma or any other pulmonary disease, whether they had been physician-diagnosed with asthma, whether they experienced symptoms such as shortness of breath/difficult breathing/dyspnea, how often these symptoms manifested and from what stimuli they were caused. Data from subjects included in the study were divided into two groups: the physiciandiagnosed asthmatics and symptomatic undiagnosed subjects in one group and the nonasthmatic/no shortness of breath control group.

\section{CRP Assessment}

Blood was drawn from study recruits, allowed to clot $\left(30-45 \mathrm{~min}, 23^{\circ} \mathrm{C}\right)$ and centrifuged $(3,500 \mathrm{rpm}, 10$ min) to separate serum and cellular components. Sera were frozen at $-20^{\circ} \mathrm{C}$ until quantitative assessment of CRP was performed. CRP quantitation was performed using a high sensitivity (hs) CRP analysis which was an enzyme linked immunosorbent assay (ELISA) sandwich methodology (Helica Biosystems, Inc., Fullerton, CA). Briefly, wells of a 96-well microplate were coated with affinity purified rabbit anti-human CRP-IgG antibody. Diluted serum was added to each well and CRP present in the sample bound the CRP antibody coating the microplate. An enzyme-conjugated secondary antibody (horseradish peroxidase labeled rabbit anti-human CRP-IgG (Helica ${ }^{\text {тM }}$ Biosystems) was added to form the antibody-antigen-antibody sandwich. Amount of CRP in the serum was directly proportional to the color intensity of the enzyme reaction detectable by absorbance at $450 \mathrm{~nm}$ using a microplate reader. Absorbance readings obtained from known CRP standards were used to create a standard curve and a linear regression was calculated. Absorbance values of participants' sera were plotted against the linear regression of the standard curve and serum CRP levels were determined.

\section{Statistics}

Using serum CRP concentrations determined on all study participants, comparisons were performed between the non-asthmatic/no shortness of breath individuals and those participants who were diagnosed asthmatics/symptomatic undiagnosed asthmatics. These comparisons were accomplished through statistical analysis using the Instat program (GraphPad Software, Inc). An unpaired t-test with an alpha set at 0.05 compared the differences between the means of the two groups. Data are reported as the mean \pm SEM.

\section{RESULTS \\ Study Recruits}

The demographics of the human volunteers recruited into the study were consistent with St. Louis and university population demographics. Composition of the study cohort (Table 1) was predominantly male, Caucasian and 18-22 years of age. Self-reporting asthmatic status indicated that $44 \%$ of the study recruits had physician-diagnosed asthma or undiagnosed frequent breathlessness while the remaining $56 \%$ had no asthma-like symptoms (Table 1).

Table 1: Study Population Demographics (Total Cohort $=49$ participants)

\begin{tabular}{lrr}
\hline & $\begin{array}{c}\text { Number of } \\
\text { Participants }\end{array}$ & $\begin{array}{c}\text { Percent of } \\
\text { Participants }\end{array}$ \\
\hline $\begin{array}{l}\text { Gender } \\
\quad \text { Female }\end{array}$ & 19 & $39 \%$ \\
$\quad$ Male & 30 & $61 \%$ \\
Ethnicity & 43 & $88 \%$ \\
$\quad$ White Caucasian & 1 & $2 \%$ \\
$\quad$ Black or African American & 1 & $2 \%$ \\
$\quad$ Hawaiian or Pacific Islander & 3 & $6 \%$ \\
$\quad$ Asian & 1 & $2 \%$ \\
$\quad$ Hispanic or Latin & & \\
Age $\quad$ & 29 & $59 \%$ \\
$\quad$ 18-22 years & 9 & $19 \%$ \\
$\quad$ 23-40 years & 11 & $22 \%$ \\
$\quad$ 41-59 years & & \\
Asthma/Shortness of Breath Status & 11 & $22 \%$ \\
$\quad$ Diagnosed Asthma & 11 & $22 \%$ \\
$\quad$ Chronic Shortness of Breath & 27 & $56 \%$ \\
$\quad$ No Asthma/No Shortness of Breath & \\
&
\end{tabular}

\section{Quantitative CRP Results}

In the current study, serum CRP levels ranged from undetectable (reported as zero) to $22,013 \mathrm{ng} / \mathrm{mL}$. Two groups were identified from the study population based upon their responses to questions related to shortness of breath. The groups were defined as: (i) non-asthmatic/ no shortness of breath control group $(\mathrm{n}=27)$; and (ii) diagnosed asthmatic/symptomatic undiagnosed asthmatic experiencing frequent shortness of breath group $(\mathrm{n}=$ 22). Means and standard errors of the means calculated for both groups yielded results of $1741 \pm 467 \mathrm{ng} / \mathrm{ml}$ for 


\section{RESEARCH AND REPORTS}

the control group and $4203 \pm 1323 \mathrm{ng} / \mathrm{ml}$ for the test group (Figure 1). A statistically significant difference $(p=0.0321)$ was noted between the two groups.

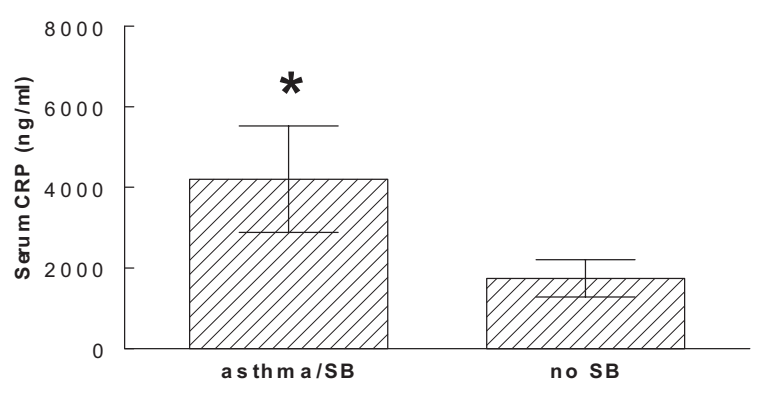

Figure 1. Individuals with diagnosed asthma or self-reported dyspnea or shortness of breath (SB) have significantly higher serum CRP levels than the control group. Results displayed are mean comparisons of asthma/shortness of breath $(n=22)$ and the control group that had no self-reported shortness of breath or diagnosed asthma $(\mathrm{n}=27) .{ }^{*}=\mathrm{p}<0.05$ between the two groups.

\section{DISCUSSION}

In the current study, the significance of increased CRP levels in asthmatic/shortness of breath individuals was assessed. Results showed that CRP levels were significantly increased in individuals with physiciandiagnosed asthma or self-reported breathlessness compared to the control group who reported no problems with breathlessness or asthma. This finding supports the hypothesis that asthma causes a significant serum CRP increase in affected individuals even in the absence of recent asthmatic attack or breathlessness episode. While the serum CRP levels of the asthma/shortness of breath group were only slightly elevated, a statistically significant elevation was noted indicating the presence of chronic low-level systemic inflammation.

Independent studies conducted by Olafsdottir, ${ }^{10}$ Takemura, ${ }^{11}$ Fujita $^{12}$ and Kony ${ }^{13}$ and their associates have revealed a correlation between elevated CRP levels and asthma. The present study was unique because in addition to considering physician-defined asthmatic status of the study recruit, it was recognized that many people suffer from breathlessness but have not been diagnosed by a physician, probably due to underdiagnosis of this condition or not seeking medical attention. Also included in the physician-diagnosed asthmatic group of the present study were those individuals reporting frequent shortness of breath/dyspnea caused by a variety of triggers such as allergens, weather conditions, exercise and perfumes/ odors. Based upon participants' responses on the questionnaire, it is suspected that many of the study recruits suffered from undiagnosed, allergen- or exercise-induced asthma.

Since the relationship between asthma and CRP is very complex, several other confounding factors may make a contribution to increased CRP levels. As stated in the introduction, CRP is elevated in individuals who are obese, smoke and/or have cardiovascular disease. ${ }^{9}$ The main link between CRP and these conditions is the underlying chronic inflammatory state of these individuals. It is sometimes hard to discern which condition is causing the increase in CRP level because CRP is a sensitive, though non-specific, marker of inflammation. ${ }^{8}$

Although a clear relationship has yet to be established, it is quite plausible that asthma and obesity are related. Many argue that asthma is caused by an individual's obesity while others argue that it is the obesity that causes the person's asthma. ${ }^{14}$ Either way, with a variable such as obesity, it is difficult to discriminate whether the increased CRP level is due to asthma, obesity or a combination of both.

Another factor to be considered is the medication regimen of the study participants. Though our questionnaire did not contain specific questions regarding asthma medication, it is recognized that many of the diagnosed asthmatic participants were probably on inhaled corticosteroids to control their shortness of breath. The interaction of the corticosteroids with IL$1 \beta$ and IL-6 results in decreased levels of the interleukins thereby resulting in decreased CRP levels. ${ }^{7}$ It is also recognized that some study participants may have had recent use of anti-inflammatory agents, despite efforts by the research team to minimize this likelihood. These anti-inflammatory drugs may have falsely lowered CRP levels in participants reporting their use and may have falsely lowered the overall means for the 


\section{RESEARCH AND REPORTS}

asthmatic/shortness of breath group and/or the non asthmatic/no shortness of breath group.

Despite these confounding factors, many studies support the hypothesis that asthma alone causes increases in serum CRP. ${ }^{10,11,12,13}$ In fact, a study conducted by Olafsdottir and associates showed that even after correcting for body mass index, the subgroup of nonallergic asthmatics still had significantly increased CRP levels as compared to the nonasthmatic participants. ${ }^{10}$ Kony and associates also reported that after adjusting for confounding factors, increased CRP levels are strongly and independently associated with respiratory impairment and bronchial hyperresponsiveness. ${ }^{13}$ Thus, results of the current study support reports of others that increased CRP levels are significantly associated with asthmatic participants but not with nonasthmatic individuals. In addition, this report identifies that undiagnosed asthmatics (that is, those who self-report frequent periods of breathlessness) also have increased serum CRP levels, despite the absence of episodic pulmonary events. Further research with CRP and asthmatics may lead to recognition of new biomarkers or other factors affecting CRP levels, a therapeutic use for CRP in asthmatics or identification of a causative mechanism for asthma. In the future, CRP may prove useful in diagnostic testing for those at risk for or already diagnosed with asthma.

\section{REFERENCES}

1. Masoli M, Fabian D, Holt S, Beasley R. Global burden of asthma: executive summary of the Global Initiative for Asthma Dissemination Committee Report. Allergy 2004;59:469-78.
2. Mathur SK, Busse WW. Asthma: diagnosis and management. Med Clin North Am 2006;90:39-60.

3. Wenzel SE. Asthma: defining of the persistent adult phenotypes. Lancet 2006;368:804-13.

4. Büyüköztürk $S$, Gelincik AA, Genç $S$, Koçak H, Oneriyidogan Y, Erden S, et al. Acute phase reactants in allergic airway disease. Tohoku J Exp Med 2004;204:209-13.

5. Arif AA, Delclos GL, Colmer-Hamood J. Association between asthma, asthma symptoms and C-reactive protein in US adults: Data from the national health and nutrition examination survey, 1999-2002. Respirology 2007;12:675-82.

6. Pepys MB, Hirschfield GM. C-reactive protein: a critical update. J Clin Invest 2003;111:1805-12.

7. Ceciliani F, Giordano A, Spagnolo V. The systemic reaction during inflammation: the acute-phase proteins. Protein Pept Lett 2002;9:211-23.

8. Black S, Kushner I, Samols D. C-reactive protein. J Biol Chem 2004;279: 48487-90.

9. Heuertz RM. Mediation of cardiovascular disease by inflammation: a look at C-reactive protein as an indicator. ADVANCE for Med Lab Professionals 2007;19:15-22.

10. Olafsdottir IS, Gislason T, Thjodleifsson B, Olafsdottir I, Gislason D, Jogi $\mathrm{R}$ et al. $\mathrm{C}$ reactive protein levels are increased in non-allergic but not allergic asthma: a multicenter epidemiological study. Thorax 2005;60: 451-4.

11. Takemura M, Matsumoto H, Niimi A, Ueda T, Matsuoka H, Yamaguchi $\mathrm{M}$, et al. High sensitivity C-reactive protein in asthma. Eur Respir J 2006;27:908-12.

12. Fujita M, Ueki S, Ito W, Chiba T, Takeda M, Saito N, et al. C-reactive protein levels in the serum of asthmatic patients. Ann Allergy Asthma Immunol 2007;99:48-53.

13. Kony S, Zureik M, Driss F, Neukirch C, Leynaert B, Neukirch F. Association of bronchial hyperresponsiveness and lung function with C-reactive protein (CRP): a population based study. Thorax 2004;59:892-6.

14. Camargo CA, Weiss ST, Zhang S, Willett WC, Speizer FE. Prospective study of body mass index, weight change and risk of adult-onset asthma in women. Arch Intern Med 1999;159:2582-8.

The peer-reviewed Research and Reports Section seeks to publish reports of original research related to the clinical laboratory or one or more subspecialties, as well as information on important clinical laboratory-related topics such as technological, clinical, and experimental advances and innovations. Literature reviews are also included. Direct all inquiries to David $L$ McGlasson MS, MLS, 59th Clinical Research Division/SGRL, 2200Berquist Dr., Bldg. 4430, Lackland AFB TX 782369908, david.mcglasson@lackland.af.mil

Clinical Laboratory Science encourages readers to respond with thoughts, questions, or comments regarding these articles. Email responses to westminsterpublishers@comcast.net. In the subject line, please type the journal issue and lead author such as "CLIN LAB SCI 23(4) RE PELLIZZARO". Selected responses may appear in the Dialogue and Discussion section in a future issue. Responses may be edited for length and clarity. We look forward to hearing from you. 